\title{
ADHERENCE TO MANAGEMENT IN PATIENTS WITH END STAGE RENAL DISEASE
}

\author{
Sheharyar Raashid, Abdul Rehman Arshad*, Abdul Wahab Mir \\ Pak Emirates Military Hospital/National University of Medical Sciences (NUMS) Rawalpindi Pakistan, *Combined Military Hospital Peshawar/National \\ University of Medical Sciences (NUMS) Pakistan
}

\begin{abstract}
Objective: To document overall adherence to haemodialysis, medications, fluid restriction and dietary prescription in patients with end-stage renal disease and to study factors that could predict poor adherence.

Study Design: Cross-sectional analytical study.

Place and Duration of Study: Department of Nephrology, Pak Emirates Military Hospital, Rawalpindi, from Jul to Sep 2018. Methodology: Adult patients on haemodialysis for at least three months were selected using consecutive sampling technique. Patients with acute kidney injury, patients on haemodialysis for less than 3 months, those on infrequent haemodialysis and unwilling patients were excluded. Demographic data was recorded. Adherence to management was assessed by administering End Stage Renal Disease Adherence Questionnaire in direct face- to-face interviews.

Results: There were a total of 101 patients having a mean age of $51.05 \pm 13.80$ years. Median haemodialysis vintage was 9 months (interquartile range 3-24 months). Mean adherence scores were $970.54 \pm 149.43$. Mean perception scores were $7.22 \pm$ 1.37. Only $49(48.51 \%)$ patients had good adherence, whereas $52(51.49 \%)$ had poor adherence to management. Increasing age was associated with poor adherence $(\beta=-0.038$; Odds Ratio $=0.963,95 \%$ CI $0.928-1.000, p=0.048)$. No other demographic parameter could predict poor adherence.

Conclusion: Non-adherence to different aspects of management plan was a significant problem, more so in younger patients.
\end{abstract}

Keywords: Medication adherence, Haemodialysis, Patient compliance.

This is an Open Access article distributed under the terms of the Creative Commons Attribution License (https://creativecommons.org/licenses/by-nc/4.0/), which permits unrestricted use, distribution, and reproduction in any medium, provided the original work is properly cited.

\section{INTRODUCTION}

End stage renal disease (ESRD) is an important cause of morbidity and mortality worldwide. As per the 2017 Global Burden of Disease study, kidney diseases account for 1.2 million deaths worldwide, and the all-age mortality associated with chronic kidney disease has risen by $41.5 \%$ between 1990 and 2017, making it one of the major rising causes of death globally ${ }^{1}$. There is paucity of data on the total number of ESRD cases in Pakistan due to lack of proper registries but it is estimated that the annual incidence of new ESRD cases is greater than hundred per million population ${ }^{2}$. Prevalence of $16.6 \%-25 \%$ has been reported in studies based on health screening camps in Pakistan ${ }^{3}$.

Management of ESRD is multifaceted. Of the different therapeutic aspects, renal replacement therapy (haemodialysis being most prevalent in Pakistan) is the primary one. Also included are the domains of pharmacological treatment, fluid restriction and dietary control, amongst a few others. Given the requirement of clinging to so many things, it becomes difficult for patients to comply with physicians' instructions in the long run. We also know that poor compliance to management would add to the morbidity and mortality ${ }^{4}$.

Correspondence: Dr Abdul Rehman Arshad, Classified Medical Specialist and Nephrologist, CMH Peshawar Pakistan

Received: 03 Jul 2019; revised received: 29 Oct 2019; accepted: 26 Nov 2019
Such patients require more hospital admissions, adding to healthcare costs.

Despite extensive literature on adherence patterns amongst ESRD patients from the rest of the world, data from Pakistan is scarce. A study done at Sindh Institute of Urology and Transplant, Karachi, noted that $18 \%$ patients dropped out of the haemodialysis program, whereas $13.4 \%$ had irregular attendance at haemodialysis sessionsduring 20145. This study was therefore designed to determine the severity of this problem in ESRD patients at our centre. We also wanted to identify factors that could predict poor adherence, so that greater emphasis could be placed on selected patients to improve compliance to management plans.

\section{METHODOLOGY}

This cross-sectional analytical study was carried out at Nephrology department, Pak Emirates Military Hospital, Rawalpindi, from July to September 2018. Approval of study design was obtained from Ethics Review Committee of the hospital beforehand vide reference number A/28 dated 21 Jun 2018. Adult patients with ESRD on maintenance haemodialysis for at least three months were selected from the haemodialysis unit using consecutive sampling technique. A minimum sample size of 103 patients was calculated with Free Statistics Calculator version 4, assuming f2: 0.15, a: 0.80 , seven predictors and probability level of 0.05 . 
All patients were included with their written consent. We excluded patients with acute kidney injury, patients on haemodialysis for $<3$ months, those on in frequent haemodialysis and unwilling patients. Demographic data was collected from all the patients, focusing especially on age, gender, education, duration and frequency of haemodialysis, monthly household income and availability of attendants.

Adherence to management was assessed using end stage renal disease adherence questionnaire (ERSD-AQ). This gauges treatment adherence in 4 areas, including adherence to dialysis sessions, prescribed medication, fluid and dietary intake restrictions. There are 46 questions divided into 5 sections. The adherence behaviour is scored by summing the responses to 6 specific questions (numbers 14, 17, 18, 26, 31 and 46). These questions carry maximum total score of 1200, with higher scores indicating better adherence. The questionnaire was administered to patients in direct face-to-face interviews by a single doctor.

Data was analysed using SPSS-20. For the purpose of this study, adherence scores up to 999 reflected poor adherence, whereas higher scores were indicative of good adherence. Frequencies of good and poor adherence were calculated and binary logistic regression was used to determine the relationship of different variables with poor adherence. All variables with $p$ values $>0.10$ on univariate analysis were excluded from multivariate analysis. For univariate and multivariate regression analysis, $p$-values $\leq 0.05$ were considered statistically significant. Perception of patients about the importance of adherence to various treatment modalities was assessed by summing the responses to questions 11, 22, 32 and 41. All of these have 5 possible options, which were grouped into three: little/not important, moderately important and highly/very important. Marks of $0,1 \& 2$ respectively were allotted for these responses.

Table-III: Factors associated with adherence behaviour.

\begin{tabular}{|c|c|c|c|c|}
\hline \multirow{2}{*}{ Parameter } & \multicolumn{2}{|c|}{ Univariate Analysis } & \multicolumn{2}{|c|}{ Multivariate Analysis } \\
\hline & OR $(95 \% \mathrm{CI})$ & $p$-value & OR $(95 \% \mathrm{CI})$ & $p$-value \\
\hline Age & $0.966(0.938-0.996)$ & 0.026 & $0.963(0.928-1.000)$ & 0.048 \\
\hline Gender* & $2.640(0.855-8.154)$ & 0.092 & $3.134(0.827-11.883)$ & 0.093 \\
\hline Duration of haemodialysis & $0.999(0.987-1.011)$ & 0.864 & - & - \\
\hline Frequency of haemodialysis** & $0.508(0.228-1.131)$ & 0.097 & $0.993(0.366-2.693)$ & 0.989 \\
\hline Education*** & $0.611(0.272-1.374)$ & 0.237 & $1.158(0.441-3.040)$ & 0.766 \\
\hline Diabetes $^{* * * *}$ & $0.730(0.303-1.756)$ & 0.482 & - & - \\
\hline Income $e^{* * * *}$ & $0.595(0.236-1.504)$ & 0.273 & - & - \\
\hline Availability of attendant $t^{* * * * *}$ & $1.562(0.681-3.585)$ & 0.293 & - & - \\
\hline
\end{tabular}

\section{RESULTS}

There were a total of 101 patients having a mean age of $51.05 \pm 13.80$ years. Median haemodialysis vintage was 9 months (inter quartile range 3-24 months). Rest of the baseline characteristics are shown in table-I. Mean adherence scores were $970.54 \pm 149$.43. The breakup of scores for the 6 questions is shown in table-II.

Table-I: Baseline characteristics.

\begin{tabular}{|c|c|c|}
\hline Variables & \multicolumn{2}{|c|}{ Frequency (\%) } \\
\hline \multirow{2}{*}{ Gender } & Male & $84(83.17 \%)$ \\
\hline & Female & $17(16.83 \%)$ \\
\hline \multirow{2}{*}{$\begin{array}{l}\text { Frequency of } \\
\text { haemodialysis }\end{array}$} & Twice a week & $58(57.43 \%)$ \\
\hline & Thrice a week & $43(42.57 \%)$ \\
\hline \multirow{2}{*}{ Education } & Up to Middle school & $39(38.61 \%)$ \\
\hline & High school and above & $62(61.39 \%)$ \\
\hline \multirow{2}{*}{ Diabetes } & Yes & $28(27.72 \%)$ \\
\hline & No & $73(72.28 \%)$ \\
\hline \multirow{2}{*}{$\begin{array}{l}\text { Monthly } \\
\text { Income (Rs.) }\end{array}$} & $<30,000$ & $77(76.24 \%)$ \\
\hline & $30,000-60,000$ & $24(23.76 \%)$ \\
\hline \multirow{2}{*}{$\begin{array}{l}\text { Availability of } \\
\text { attendant }\end{array}$} & Yes & $67(66.34 \%)$ \\
\hline & No & $34(33.66 \%)$ \\
\hline \multicolumn{3}{|c|}{ Table-II: Mean adherence scores. } \\
\hline $\begin{array}{c}\text { Question } \\
\text { No. }\end{array}$ & Adherence & Mean \pm SD \\
\hline 14 & Haemodialysis-attendance & $\begin{array}{c}259.90 \pm \\
75.84 \\
\end{array}$ \\
\hline 17 & $\begin{array}{l}\text { Episode of shortening } \\
\text { haemodialysis }\end{array}$ & $\begin{array}{c}168.32 \pm \\
54.64\end{array}$ \\
\hline 18 & $\begin{array}{l}\text { Duration of shortening } \\
\text { haemodialysis }\end{array}$ & $\begin{array}{l}77.48 \pm \\
35.62\end{array}$ \\
\hline 26 & Adherence to medication & $\begin{array}{c}182.67 \pm \\
32.74\end{array}$ \\
\hline 31 & $\begin{array}{l}\text { Adherence to fluid } \\
\text { restriction }\end{array}$ & $\begin{array}{c}134.16 \pm \\
54.28\end{array}$ \\
\hline 46 & $\begin{array}{l}\text { Adherence to dietary } \\
\text { restriction }\end{array}$ & $\begin{array}{c}148.02 \pm \\
46.33\end{array}$ \\
\hline
\end{tabular}

Only $49(48.51 \%)$ patients had good adherence, whereas $52(51.49 \%)$ had poor adherence to management. Increasing age was associated with reduced adherence $(\beta=-0.038$; Odds Ratio $=0.963,95 \%$ CI $0.928-1.000, p=$ 
0.048). None of the other parameters could predict this. Results of univariate and multivariate binary logistic regression are displayed in table-III. Mean perception scores were $7.22 \pm 1.37$. A vast majority of patients were aware of the importance of different management aspects such as adherence to dialysis sessions and medications, as well as fluid and dietary restrictions. Details are depicted in figure.

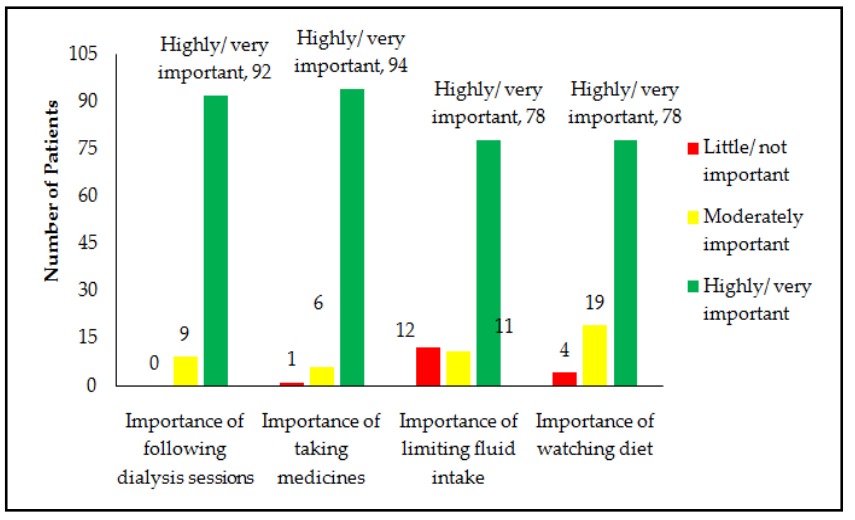

Figure: Perception about importance of adherence.

\section{DISCUSSION}

Adherence to treatment plays a pivotal role in enhancing survival of patients undergoing haemodialysis. Non-adherence is directly proportional to the complexity and duration of a given medical condition ${ }^{6}$. This remains a major challenge even in developed countries. There is a huge variation in reported figures, depending on the definition used and the measurement tools applied. A systemic review reported 7.9-8.5\% skipped haemodialysis treatments in US, $19.6-20.3 \%$ frequency for shortened treatments, medication non-adherence ranging from $15.4-50.2 \%$, fluid non adherence from $9.7-49.5 \%$ and diet non-adherence in haemodialysis patients ranging from $9-22.1 \%{ }^{7}$. The underlying reasons are not just psychological. Indeed, the metabolic derangements associated with ESRD also play an important part $^{8}$.

Of the problems suffered by haemodialysis patients, the severest is non-adherence to fluid restriction ${ }^{9}$. On the other hand, missing dialysis sessions or shortening them has the strongest association with mortality ${ }^{10}$. A greater proportion of our patients understood the importance of attending dialysis sessions and taking regular medications than adhering to recommended fluid allowances and dietary suggestions.

A study done in palestine using the same questionnaire as ours revealed good adherence in 55.5\% cases $^{11}$. Almost three-fourth (72.4\%) patients were non- adherent to at least one aspect of the therapeutic strategy in a Portuguese study using ESRD-AQ ${ }^{12}$.

Elderly people were more likely to be compliant to the management plan. Several studies have previously documented better compliance to diet and fluid in elderly people $\mathrm{e}^{13-15}$. It has been suggested that the dietary intake reduces as older people become less independent, thus making them more compliant to suggested restrictions. A study done at our hospital in 2016 documented better quality of life in younger patients, with each increasing year of age associated withalmost $5 \%$ reduction in kidney disease component summary score $^{16}$. Such patients probably have more activesocial lives, and have more distractions preventing better compliance.

A study done by Chan et al, found out that male patients were more likely to be non-compliant with dietary restrictions as compared tofemales ${ }^{17}$, Similarly, younger male haemodialysis patients were more prone to be non- adherent to diet and fluid restrictions ${ }^{18}$. However, this was not the case in this study. There was no significant relationship between gender and non-adherence, analogous to what has previously been reported by Ibrahim et al ${ }^{19}$. We attribute this to the fact that none of the patients included in this study worked /was employed, so that there was no distraction in attending haemodialysis sessions.

There was no impact of monthly income on nonadherence levels. This is probably because the vast majority of our study population was entitled to free medical treatment including haemodialysis at our centre. Level of education did not correlate with non-adherence. Mukakarangwa et al, documented similar findings in Rwanda, where factors such educational level and monthly income were not significantly associated with adherence to haemodialysis in ESRD population $^{20}$. Dialysis vintage did not impact non-adherence rates. The same was observed by Russell et al, and Khalil et al, who documented only dietary and fluid adherence using the Dialysis Diet and Fluid Questionnaire ${ }^{21,22}$. Frequency of haemodialysis and the presence of diabetes were also not related to non-adherence in our patients. This is generally in keeping with the notion that research done in the past has generally failed to identify demographic or psychosocial factors consistently associated with non-adherence ${ }^{23}$.

It has been suggested that having family and social support improves adherence to treatment ${ }^{24}$. There was no difference in adherence rates amongst patients who came to dialysis centre with attendants compared 
to those who attended dialysis sessions alone. Our cultural values dictate the presence of attendants with most of the patients. We know that attending frequent haemodialysis sessions is quite demanding for close family members of patients. Though we do not have objective data to support our notion, it is very much possible that patients coming to dialysis centre alone were physically and emotionally stronger and be able to take care of themselves reasonably well. Moreover, their coming alone to the hospital does not exclude good family support at home beyond the haemodialysis treatment hours.

The ESRD-AQ is meant to be self- administered. However, we administered them in direct face to face interviews because of poor literacy and comprehension of our study population. While this reduced missing responses significantly, we feel that this made data collection more time consuming and resource intensive. A single doctor administered this questionnaire to all the patients, thus excluding inter- observer variability bias.He was trained to strictly adhere to the questionnaire during the interviews so as to reduce information bias.

\section{LIMITATION OF STUDY}

Though our centre provides free of cost haemodialysis facilities to all dependent clientele, we did not record data regarding expenses incurred by patients on account of travelling between their homes and the hospital. Patients were recruited from a single centre only, implying that extrapolating the results to other centres may not be possible. Assessment of adherence is both subjective and objective. This study has achieved good subjective assessment.

However, considering limited resources, we did not collect other objective clinical data including interdialytic weight gain or laboratory parameters like serum albumin and potassium. Thus, though we could assess overall adherence, we could not particularly comment on adherence to diet, medications, and fluidrestriction in specific. Lastly, disparity between objective and subjective assessment of adherence is well known, a fact that questions the utility of assessment tools like the one used in this study.

\section{CONCLUSION}

Adherence to ESRD management remains a challenging problem, with nearly half of the patients defaulting on different aspects of the therapeutic plan. This problem is more pronounced in younger patients.

\section{CONFLICT OF INTEREST}

This study has no conflict of interest to be declared by any author.

\section{REFERENCES}

1. GBD Chronic Kidney Disease Collaboration. Global, regional, and national burden of chronic kidney disease, 1990-2017: a systematic analysis for the Global Burden of Disease Study 2017. Lancet 2020; 395(10225): 709-33.

2. Ullah K, Butt G, Masroor I, Kanwal K, Kifayat F, Patel J, et al. Epidemiology of chronic kidney disease in a Pakistani population. Saudi J Kidney Dis Transpl 2015; 26(6): 1307-10.

3. Imran S, Sheikh A, Saeed Z, Khan SA, Malik AO, Patelet J, et al. Burden of chronic kidney disease in an urban city of Pakistan, a cross-sectional study. J Pak Med Assoc 2015; 65(4): 366-69.

4. Alikari V, Matziou V, Tsironi M, Kollia N, Theofilou P, Aroni A, et al. A modified version of the Greek simplified medication adherence questionnaire for haemodialysis patients. Health Psychol Res 2017; 5(1): 6647-50.

5. Mazhar F, Nizam N, Fatima N, Siraj S, Rizvi SA. Problems associated with access to renal replacement therapy: Experience of the Sindh Institute of Urology and Transplantation. Exp Clin Transplant 2017; 15 (Suppl-1):46-49.

6. Mc Donald HP, Garg A, Haynes RB. Interventions to enhance patient adherence to medication prescriptions: scientific review. JAMA 2002; 288(22): 2868-79.

7. Matteson ML, Russell C. Interventions to improve haemodialysis adherence: a systematic review of randomized-controlled trials. Hemodial Int 2010; 14(4): 370-82.

8. Ovayolu N, Ucan O, Pehlivan S, Yildizgordu E. Relationship between adaptation to treatment and diet with some blood results of haemodialysis patients. Firat Saglık Hizmetleri Dergisi 2007; 2(2): 93-99.

9. Başer E, Mollaoğlu M. The effect of a haemodialysis patient education program on fluid control and dietary compliance. Hemodial Int 2019; 23(3): 392-401.

10. Kim Y, Evangelista LS, Phillips LR, Pavlish C, Kopple JD. The end-stage renal disease adherence questionnaire (ESRD-AQ): testing the psychometric properties in patients receiving in-center haemodialysis. Nephrol Nurs J 2010; 37(4): 377-93.

11. Naalweh KS, Barakat MA, Sweileh MW, Al-Jabi SW, Sweileh WM, Zyoud SH. Treatment adherence and perception in patients on maintenance haemodialysis: a cross - sectional study from Palestine. BMC Nephrol 2017; 18(1): 178-81.

12. Poveda V, Amado L, Filgueiras M, Teixeira L, Miranda V, Santos-Silva A, et al. End-stage renal disease adherence questionnaire: translation and validation to the Portugese language. Ren Fail 2016; 38(10): 1633-38.

13. Nakao RT, Gorayeb R, da Costa JAC. Factors associated with treatment adherence of Brazilian patients undergoing haemodialysis. Actualidades en Psicología 2016; 30(121): 77-90.

14. Alkatheri AM, Alyousif SM, Alshabanah N, Albekairy AM, Alharbi S. Medication adherence among adult patients on haemodialysis. Saudi J Kidney Dis Transpl 2014; 25(4): 762-68.

15. Dantas LG, Cruz C, Rocha M, Moura JA Jr, Paschoalin E, Paschoalin S, et al. Prevalence and predictors of nonadherence to haemodialysis. Nephron Clin Pract 2013; 124(1-2): 67-71.

16. Arshad AR, Khan G, Amjad Z, Butt B, Islam F, Qayyum M, et al. Predicting quality of life in haemodialysis patients. Pak Armed Forces Med J 2019; 69(1): 175-81.

17. Chan YM, Zalilah MS, Hii SZ. Determinants of compliance behaviours among patients undergoing haemodialysis in Malaysia. Plos One 2012; 7(8): e41362-65. 
18. Kugler C, Vlamick H, Haverich A, Maes B. Nonadherence with diet and fluid restrictions among adults having haemodialysis. J Nurs Sch 2005; 37(1): 25-29.

19. Ibrahim S, Hossam M, Belal D. Study of non-compliance among chronic haemodialysis patients and its 'impact on patients' outcomes. Saudi J Kidney Dis Transpl 2015; 26(2): 243-49.

20. Mukakarangwa MC, Chironda G, Bhengu B. Adherence to haemodialysis and associated factors among end stage renal disease patients at selected nephrology units is Rwanda: a descriptive cross- sectional study. Nurs Res Pract 2018; 2018(1): 4372716-19.
21. Russell CL, Knowles N, Peace L. Adherence in dialysis patients: A review of the literature. J Nephrol Soc Work 2007; 27(1): 11-44.

22. Khalil AA, Frazier SK, Lennie TA, Sawaya BP. Depressive symptoms and dietary adherence in patients with end- stage renal disease. J Ren Care 2011; 37(1): 30-39.

23. Mello L, Regan D,Curtis R. Factors influencing adherence among Irish haemodialysis patients. Educ Couns 2013; 92(1): 88-93.

24. Efe D, Kocaoz S. Adherence to diet and fluid restriction of individuals on haemodialysis treatment and affecting factors in Turkey. JPN J Nurs Sci 2015; 12(2): 113-23. 